\title{
Research on LC Design of Interior Public Space
}

\author{
Longlong Zhang \\ Tianjin Polytechnic University \\ Tianjin, China
}

\author{
Ying Song \\ Tianjin Polytechnic University \\ Tianjin, China
}

\begin{abstract}
With the rapid development of the global economy nowadays, it is imperative for us to take actions to solve such environment problems as environmental deterioration, ecological imbalance and so on. Therefore, the concept of environmental protection is applied to the environmental design, including consumption environment, consumption quality and environmental protection design. And in order to implement such idea in the design of interior public spaces, this paper focuses on deliberating the interior decoration with the characteristics of the green and low-carbon design with the style of cultural regression, advanced technology, and simplicity, which aiming at not only satisfying the functional demands but also promoting the green and lowcarbon development in design field and abandoning design methods of the traditional high energy consumption.
\end{abstract}

Keywords-ecological civilization; environmental protection; friendly; low-carbon design; environmental design; sustainable development

\section{INTRODUCTION}

The social development is coupled with various environmental problems such as environmental pollution and ecological unbalance, etc. The players, including the state and individuals, should place a high premium on environmental protection, so should interior design of public space. The designer has the responsibility to lead the design industry to develop towards green, low carbon, humanization, prioritizing soft decoration over hard decoration and cyclic utilization, which are sustainable design directions. Therefore, the application of LC, green, environmental and energy-saving materials is supposed to be the fountainhead for the design language of each designer, to contribute a share with own professional capacity to the environmental protection.

\section{CONNOTATION OF LC DESIGN}

Recent years witnessed development of LC concept in various industries, including LC design of interior and exterior, LC environmental protection of constructional materials, and sustainable development in urban construction, etc., which are all trending towards this tendency. The concept of LC interior public space refers to a decoration construction mode which applies LC and environmental decoration materials, natural accessories, efficient and emission-reducing operation to guarantee balanced decoration effect, sustainable reusing and low energy dissipation. LC-based public space design is an inexorable road to future interior design. A wide spectrum of elements, including big ones such as design of urban construction, construction materials, and small artwork like courtyard, and small ones such as door window materials, wall coating, wooden furniture in interior space, etc., are all reproducible. There are diverse ways to save energy and reduce emission, improve utilization ratio of energy efficiency, and reduce carbon emission in the whole life cycle of space, such as emission of ventilation and emission of space design, absorption of carbon dioxide by green plants, utilization of new materials, etc. The ultimate purpose of ecological design, green design, sustainable design in design process is to minimize the emission of greenhouse gases and realize sustainable utilization of materials.

\section{ANALYSIS ON APPLICATION STATUS OF LC CONCEPT TO DOMESTIC AND FOREIGN PUBLIC SPACE}

Through research and practice of a few decades, the foreign interior design circle has proved that the interior design requires more efforts compared with treatment of building structure and building system. So to speak, interior design plays a major role in living space and places of commercial activities. Just as architectural master Plattner said, "the thing more difficult than designing the buildings accommodating so-called interior space is interior design". The foreign designers have perfected LC design of interior public space from such aspects as LC energy, environmental protection and energy conservation and planning and design in design and construction, developed and utilized manifold renewable resources and developed a series of technologies of LC energy conservation design to form a new design domain which is led by new scientific materials and develops sustainably based on strategy of LC green design.

The designers in the design industry are exploring and researching $\mathrm{LC}$ economic development mode fitting Chinese situation. The domestic research on LC, green and environmental protection is mainly focused on technology levels such as energy-saving and insulating constructional materials and door window of residential houses, while few efforts have been put in research on interior design of public space. The application of LC green design is not perfect enough. Few energy-saving materials are designed with application of spatial LC design and combination of regional features. Instead, the LC concept only rests on conceptual planning of interior space and theoretical level of building design, with little practice. 


\section{PRINCIPLES OF LC CONCEPT FOR INTERIOR PUBLIC SPACE}

As finish work gradually worked onto the stage of decoration, plus people's higher aesthetic level and pursuit of spiritual enjoyment, more and more interior public space began to stress own decoration. The design more and more lays stress on details and decoration collocation. In addition, in this era advocating energy saving and environmental protection, the design should also stress environmental protection and recycling of materials to boost sustainable development. Besides, in company with technological development and informatization and networking development in modern times, the masses' requirements are trending towards sophisticated technologies, high sentiment and interactive experience. The two combine to form a kind of individualized development which values science and technology without losing the milk of human kindness. Therefore, three principles should be followed in LC design of interior public space:

- Green, environmental and sustainable development;

- Utilization of regenerative energy and use of LC environmental materials;

- Fashion, strong scientific feel and dense cultural atmosphere of enterprise;

- Macro division of space and reasonable distribution of motion line and streamline.

\section{LC DESIGN METHOD OF INTERIOR PUBLIC SPACE}

\section{A. Integration Design of Interior Public Space and the Main Building}

As part of space environment design, the interior space design is to deepen the building. The recreation of interior environment should combine the content of monolithic architectural structure, and interior space design and building design should supplement each other. While in the construction of a business environment currently, the architectural designer only designs building construction and appearance, etc. and the interior designer only make design after the monolithic architectural appearance and internal structure are completed, which is separating interior space from the building, as the design thinking for the two parts is different, leading to disharmonious design. Such unreasonable phenomenon should be changed by integrating the design of building and the interior, i.e. designing the building structure, building extension, indoor decoration materials, furniture and lighting as a whole, and integrating functional design of interior and exterior, visual design and spatial planning, to make the design of building and public space more humanized and design flow more scientific, avoid re-treatment or waste of resources, which also accords with the sustainable development strategy of ecological civilization construction.

\section{B. Utilization of Interior LC Environmental Materials and Renewable Energy}

Based on interior public space, to apply new-fashioned LC environmental renewable materials, develop and apply new materials or even to popularize in later period are of crucial importance for LC design of interior space. Investigation and research show that such LC environmental materials as fiber cement board, stalk plates, degradable plastics, hybrid straw brick, etc. can be extensively applied to interior space. These materials emits low carton and are environmental without influence on people's health. Besides, these new LC environmental materials can be recycled for use and are renewable. The traditional highly polluting and energy-consuming decoration materials should be abandoned. The new LC energy-saving and environmental materials are the development trend of LC interior design in the future.

The wind energy, geothermal energy and solar energy, etc., which are abundant and widely distributed, can be recycled and are environmental and renewable, hence fit for development and utilization in many regions. The design scheme of interior public space should use above-mentioned new energy with priority, which has no pollution, small difficulty in development and can create interaction and combination of interior space and external environment to achieve the ultimate goal of low carbon, energy saving and environmental protection.

The interior space design should give priority to use of renewable resources such as solar energy, wind energy and hydroenergy, etc. and adopt corresponding design proposal and measures. Above clean and pollution-free renewable energy does not pollute the interior environment, and can build a good interactive atmosphere between the interior and external environment to save energy and protect environment. The designers in a great many current LC space designs developed substantive technologies and modes of utilizing new energy, especially the hydroenergy and solar energy, which are worth attention or even large-scale popularization. For example, the energy in British Sigma LC residence is all renewable, such as solar water heater, water circulation system, heat recovery system, etc. Some construction waste such as metal, timber, concrete, etc. would be produced in building process, and should be recovered and classified for use.

\section{Optimize Design Structure and Functions}

Before defining design proposal, the designer should make detailed investigation and analysis on the living environment and location of designed area, and use natural photosynthesis to design lighting equipment in a good place, to use solar energy equipment as far as possible for interior illumination. The space for each interior structure should be reasonably designed to avoid space waste. In decoration process, the designer should embellish indoor environment with creative design and use LC environmental materials, to optimize design structure premised on meeting functional demand, so as to standardize operation of design and decoration. 


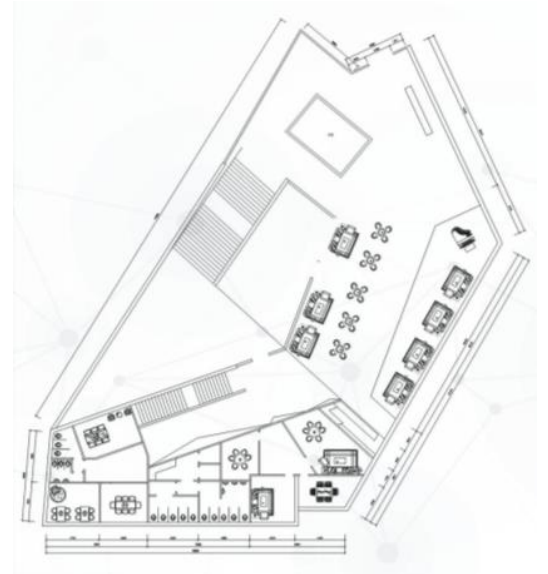

Fig. 1. CAD layout.

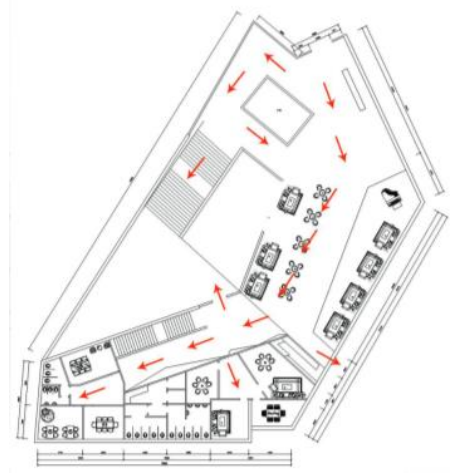

Fig. 2. Analysis chart of motion line.

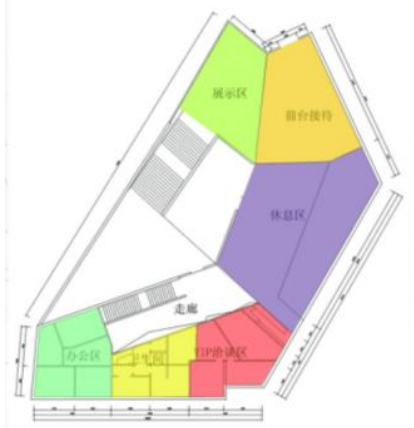

Fig. 3. Function partition map.

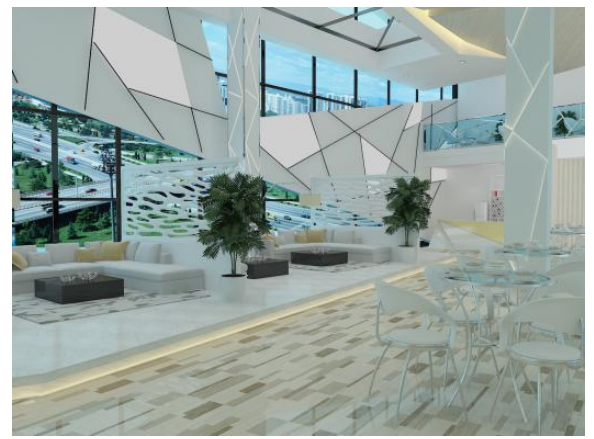

Fig. 4. Effect drawing.

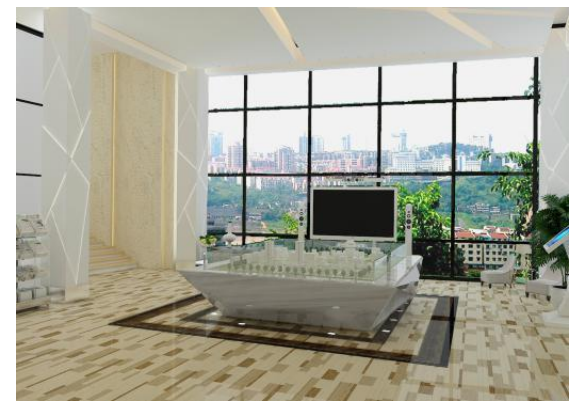

Fig. 5. Effect drawing.

Considering the project's mainly targeting the young consumers and influence of environmental materials and green consumption on people's life, the design for sale office of Xincheng International as shown in "Fig. 1", "Fig. 2", "Fig. 3", "Fig. 4", and "Fig. 5" takes environmental psychology and lamplight as breakthrough points, and analyzes people's demand and psychology. It is also found that modern younglings have a lot of reverie and aspiration for technology and future life, and our life now completely cannot get away from technology and internet. Thus this design takes "technology" and "green" as design idea and highlights a fashionable and concise style full of technologies and green and environmental elements. In the project, the design extends the core design idea of John-Portman, i.e. "harmonious unification of art and function". The design of sale office starts with division of interior space, application of materials, lamplight and hue, as well as technology application. The integrality of design and entirety of spatial style are stressed in designing, and unification of function and beauty is realized at pains. Added to this, the current energy-saving and environmental concept and application of internet are added to the design to enable the scheme to not only respond to the state's policy of environment treatment and development, but also to keep up with international design trend, which makes it the finish touch of this project.

\section{COUNTERMEASURES AND LONG TERM POTENTIAL FOR CURRENT LC DESIGN OF CHINESE INTERIOR PUBLIC SPACE}

Currently, the LC design of interior public space in China has made some achievements, with many new environmental LC materials and new technologies flooding and developing. The LC economic development will be an important development mode in future. Nonetheless, generally speaking, LC design of interior public space in China still has a large space for improvement and development.

\section{A. Countermeasures for Current LC Design of Chinese Interior Public Space}

In actual social development, the technologies of LC energy-saving, renewable energy, green and environmental protection, etc. should be developed with large input and popularized to each link of design. From the perspective of state, China adheres to scientific development concept and practices the fundamental national policies of saving energy 
and protecting environment to construct ecological civilization. Besides, the government should establish scheme for LC design, development and emission, increase technological subsidies or incentives for green, LC, energy saving and environmental protection, and perfect the laws and regulations on LC design. The developers should set up industry driving mechanism for long-run development. The LC buildings and interior design with low energy consumption and sustainable development imply a huge business opportunity, so the new energy and many energysaving development modes such as energy-saving, fuelsaving, electricity-saving, etc. should be developed emphatically to drive the healthy and positive-cycle development of the whole industry. The designer should lead the clients to adopt LC energy-saving materials in design and stress application of LC concept.

\section{B. Development Trend for Current LC Design of Chinese Interior Public Space}

The traditional design of interior public space will be bound to transform towards LC design. The current LC design of interior public space in China will shift from the traditional mode that has high dissipation of energy, uses many harmful decoration materials and wastes many resources to the LC, ecological, energy-saving and environmental mode. The LC design of interior space is an inevitable mode of sustainable development. As Chinese society is developing by leaps and bounds, the LC design conforms to the current of the times and significantly meets people's life demands, also is an important part in global economic strategy transformation. The design industry also needs the development direction of being more professional, environmental, energy-saving and scientific, while LC design has outstanding advantages in decoration cost, environmental protection, and client experience, etc. With adjustment of global energy consumption mode, development of new energy technology and change of resource structure, transformation of interior public space design towards LC design is a development trend in future, and will ultimately substitute the traditional interior public space design which consumes much energy and pollutes the environment.

\section{CONCLUSION}

Chinese LC design of interior public space is developing rapidly. We should set up thinking mode of LC economic development, lay stress on utilization of LC, energy-saving and environmental energy and apply efficient and energysaving LC materials. The integrative design of interior public space and main building and utilization of LC and environmental materials and renewable energy are also a development trend of LC design of public space in China. We can actualize development of LC concept from spatial functional design, decoration and construction, soft decorative accessories, and design of physical environment. The future interior and exterior design should also follow the concept of being green, sustainable, LC, and energy-saving and efficient, which is believed to be the development trend of Chinese industry of environmental art. To improve the environment with professional capacity to make design idea greener, design mode more environmental, and design materials more sustainable are not only the duty of our environmental art designers, but also is an obligation of common citizens.

\section{REFERENCES}

[1] Xu Liang, Dong Wanli. Interior Environment Design. Chongqing. Chongqing University Press, 2003.1.

[2] Gu Chaolin. Devleopment Mode of LC urban Planning [J]. Urban and Rural Development, 2009 (11).

[3] Wen Jiangang. LC Strategy for Contemporary Interior Design in China [J]. Furniture \& Interior Design. 2010(9).

[4] Luo Lingling. Tutorial for Development of Creation Capacity in Building Design. Beijing: China Architecture \& Building Press, 2003. 